\title{
Práticas inovadoras nas bibliotecas escolares em Florianópolis: empreendedorismo cultural em foco
}

Thayná Duarte

\author{
Bacharel em Biblioteconomia pela UDESC
}

Daniela Spudeit

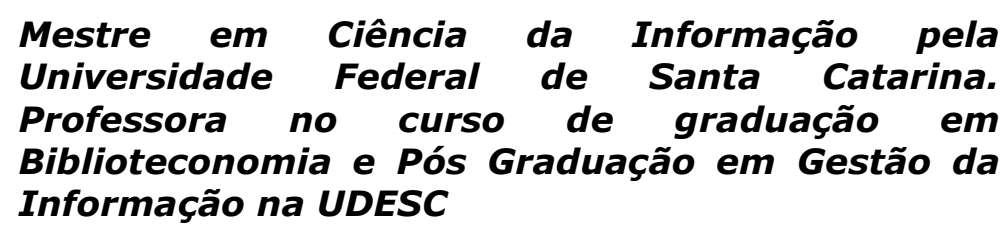

http://dx.doi.org/10.1590/1981-5344/3160

Esta pesquisa aborda a criatividade e as práticas inovadoras no contexto das bibliotecas escolares do município de Florianópolis. Dessa forma, conceitua criatividade, inovação, empreendedorismo e seus tipos, tendo como foco o empreendedorismo cultural, por caracterizar os empreendimentos planejados em bibliotecas escolares. Desta forma, teve como objetivo principal analisar as práticas inovadoras nas bibliotecas escolares públicas e privadas do município de Florianópolis. Possui caráter exploratório descritivo, com abordagem qualitativo-quantitativa. A coleta de dados foi realizada por meio de questionário online com os bibliotecários e responsáveis por bibliotecas escolares públicas registradas no site da Rede de Bibliotecas da Prefeitura do município de Florianópolis e escolas privadas afiliadas ao Sindicato das Escolas Particulares de Santa Catarina (SINEPE/SC). Além disso, foram apresentadas práticas inovadoras possíveis de executar nas bibliotecas escolares objetivando uma formação mais cidadã. Foi possível obter um panorama da situação atual do município em relação ao empreendedorismo cultural e práticas inovadoras realizadas pelas bibliotecas escolares. Conclui-se que alguns profissionais tem buscado modificar suas práticas de modo a atuar mais ativamente no ensino aprendizagem, entretanto, estas iniciativas ainda são tímidas e dependem de uma mudança proativa dos profissionais que em muitas situações deixam-se 
desmotivar pelas dificuldades não visualizando as possibilidades para empreender dentro das bibliotecas escolares. Almeja-se que este trabalho possa contribuir para despertar a mudança atitudinal necessária a estes profissionais, possibilitando assim, a transformação das bibliotecas.

Palavras-chave:

Criatividade.

Inovação.

Empreendedorismo cultural. Biblioteca escolar.

\section{Innovative practices in school libraries in Florianópolis: cultural entrepreneurship in focus}

This research deals with creativity and innovative practices in the context of school libraries in the municipality of Florianópolis. In this way, it conceptualizes creativity, innovation, entrepreneurship and its types, focusing on cultural entrepreneurship, as it characterizes the projects planned in libraries. With this, the main objective of this research is to analyze the innovative practices in the public and private school libraries of the city of Florianópolis. It has descriptive exploratory character, with qualitative-quantitative approach. Data collection was done through an online questionnaire with the librarians and responsible for public school libraries registered on the website of the Library Network of the Municipality of Florianópolis and private schools affiliated with the Santa Catarina Private School Union (SINEPE / SC). In addition, innovative initiatives found in the literature were presented to demonstrate some possible practices to be carried out in school libraries, and innovative perspectives that could be implemented in these environments were also contributed as a contribution to the training of citizens. As a result of the data collection, it was possible to obtain an overview of the current situation of the municipality in relation to cultural entrepreneurship and innovative practices carried out by school libraries. It is concluded that some professionals have tried to modify their practices in order to act more actively in teaching learning, meanwhile, these initiatives are still shy and depend on a proactive change of the professionals that in many situations are left unmotivated by the difficulties not visualizing the possibilities to undertake within school libraries. It is 
hoped that this work can contribute to awakening the necessary attitudinal change to these professionals, therefore possible, the transformation of the libraries.

Keywords: Creativity. Innovation. Cultural entrepreneurship. School library.

Recebido em 07.05.2017 Aceito em 11.07.2018

\section{Introdução}

Muitas mudanças estão acontecendo na sociedade oriundas do desenvolvimento da tecnologia, da abertura de mercados, da globalização, do volume de informações geradas e disseminadas, entre outros fatores que caracterizam a atual "sociedade da informação".

Neste contexto, a inovação e empreendedorismo são palavraschave. Inovar se tornou pré-requisito para transformação social, melhoria da qualidade de vida e um diferencial competitivo. O homem busca expandir seus conhecimentos e suas fronteiras movido pela competitividade, dessa forma, investe em empreendimentos que thes tragam alguma realização, lucro, satisfação pessoal e/ou social, entre outros.

Os empreendedores são agentes da mudança de nossa sociedade. Suas ideias e ações geralmente visam transformar nosso mundo e criar algo de novo. Muitas vezes são inovações incríveis e outras são apenas iniciativas práticas que acrescentam algo bem conhecido em um lugar onde ainda não havia sido implementado (SALIM; SILVA, 2010, p. 3).

Por meio da educação é possível adquirir habilidades e conhecimentos para tornar essa ação possível. Segundo Bastos e Ribeiro (2011), é apenas por meio da educação que a sociedade cria, inova e empreende. A educação é a chave para o progresso da sociedade moderna. Nesse bojo, a biblioteca escolar se inclui como espaço fundamental nas instituições de ensino para promover um ambiente dinâmico com acesso aos diferentes recursos e fontes de informação para que os alunos aprendam a exercer sua cidadania por meio de uma aprendizagem contínua e autônoma. As bibliotecas escolares são espaços que podem ser usados para formação e mediação de conhecimentos, para desenvolvimento de atividades que estimulem a criatividade e o senso crítico de seus interagentes, com uso do acervo, de atividades lúdicas e acadêmicas, discussões e debates, apresentações, gincanas, entre outros. Por meio do mapeamento das práticas inovadoras que podem e devem ser desenvolvidas nesse ambiente de educação e formação de cidadãos do futuro, busca-se responder a seguinte questão: As bibliotecas escolares de Florianópolis desenvolvem ações criativas e inovadoras? 
Desta forma, o objetivo geral deste trabalho foi: Analisar as práticas inovadoras nas bibliotecas escolares públicas e privadas em Florianópolis. Já os objetivos específicos foram: identificar práticas inovadoras em bibliotecas na literatura; verificar ações inovadoras realizadas nas bibliotecas da Rede Municipal de Florianópolis e descrever ações inovadoras que podem ser realizadas no âmbito das bibliotecas escolares.

\section{Criatividade e inovação}

A grande força que movimenta a engrenagem da inovação é a criatividade que impulsiona o surgimento de ideias e práticas que podem transformar-se em empreendimentos dos mais diversos tipos. A ignição do processo criativo está presente em todas as mentes humanas, e segundo Thompson (1993, p. 24) a "criatividade é a capacidade de olhar para a mesma coisa que todos os outros, mas ver algo de diferente nela". Entretanto, apesar da capacidade de ser criativo residir em todos os seres humanos, o ambiente social pode impor algumas limitações que podem criar barreiras ao processo criativo. O meio social influencia muito na criação ou desconstrução dessas barreiras.

Esses bloqueios, segundo Mariano e Mayer (2011, p. 142), podem ser de três tipos:

1. Autocensura: construídos ao longo do tempo através de situações vividas durante o processo educacional ou de socialização, construídas através de críticas, desdém, repressão de ideias diferentes [...]. Quanto maior é o desejo de agradar a todos e de ser aceito socialmente, maior é o medo das críticas. O medo de enfrentar novas situações nos leva a ter pensamentos negativos que reprimem a criatividade.

2. Limitações da percepção humana: são bloqueios do próprio cérebro, que podem nos impedir de ver o mundo de forma inovadora;

3. Bloqueios externos ou ambientais: são bloqueios que se criam sob ambientes restritivos, que forçam a exprimir a criatividade $[. .$.$] . Em alguns ambientes (empresas, escolas,$ famílias ou outros grupos sociais) a pressão para que o indivíduo se adapte a um determinado padrão é muito forte.

Estes bloqueios de criatividade são muito comuns, geralmente cultivados por experiências adversas quem podem ocorrer através dos anos, às vezes não são percebidos por que acabam sendo interiorizados, entretanto, é necessário estar ciente que esses bloqueios existem e podem ser superados, a motivação para rompe-los abre as portas para o reconhecimento da criatividade.

Modernamente a criatividade é um fator de vantagem competitiva, procurada por instituições que precisam aproveitar o capital intelectual de 
seus colaboradores que, sob a premissa de que quanto mais criativos e inovadores, mais contribuições terão a oferecer.

A criatividade está intrínseca à inovação porque para que se consiga chegar a algo inovador, o indivíduo precisa ser criativo, pois, a criatividade amplia a visão de mundo do possibilitando o surgimento de ideias inovadoras. Todavia, "nem toda ideia criativa é uma inovação" (SOUZA; LAPOLLI, 2010, p. 212).

A principal diferença entre uma ideia criativa e a efetivação de algo inovador é atribuir ação. Se uma ideia criativa for realmente valiosa, adequada, original e ainda consiga agregar valor, é necessário fazê-la acontecer, pôr em prática, partir para a realizAÇÃo. A inovação, então, ocorre a partir da concretização de uma ideia criativa, que consiga agregar valor à sociedade.

Conforme o Manual de Oslo (ORGANIZAÇÃO PARA COOPERAÇÃO ECONÔMICA E DESENVOLVIMENTO DEPARTAMENTO ESTATÍSTICO DA COMUNIDADE EUROPÉIA - OECD, 2006) a inovação pode ocorrer em qualquer setor da economia, incluindo serviços governamentais (saúde, educação, segurança); empresas (comerciais, industriais e o setor de serviços); e também no setor público. Nesse sentido, a inovação é conceituada como:

Implementação de um produto (bem ou serviço) novo ou sigficativamente melhorado, ou um processo, ou um novo método de marketing, ou um novo método organizacional nas práticas de negócios, na organização do local de trabalho ou nas relações externas (OECD, 2006, p. 55).

Além de preocupar-se com as demandas do mercado, a sociedade possui deveras necessidades sociais, para supri-las é necessário que todos os setores da sociedade se preocupem em contribuir para uma convivência harmônica que valorize todos os indivíduos e seres, diminuindo as desigualdades e caminhando para a prosperidade social. A criatividade e a inovação proporcionam ao ser humano a possibilidade de aproveitar oportunidades em prol de benefício pessoal, profissional ou social, a partir daí, os empreendimentos são criados visando atingir estes objetivos.

\section{Empreendedorismo}

O empreendedorismo está presente na história da humanidade mesmo antes de ter esta designação. O homem que desenvolve produtos e/ou serviços inovadores, assume riscos e agrega valor à sociedade, é considerado um empreendedor. Atualmente, a função do empreendedor é associada à atitude, comportamento e principalmente à inovação (DOLABELA, 2003; SALIM; SILVA, 2010).

O empreendedorismo não é um dom de poucos, ele pode ser aprendido e ensinado. Segundo Dolabela (2003, p. 16) "todos nascemos empreendedores", entretanto infelizmente, devido à exposição à valores contrários e conservadores há uma contaminação para o conformismo. 
Visando compreender qual o perfil do empreendedor os autores Salim e Silva (2010) enumeram dez características comuns aos mesmos: busca de oportunidades e iniciativa, persistência, aceitação de riscos (calculados), exigência da eficácia, eficiência e qualidade, comprometimento com o trabalho, trabalho baseado em metas, busca de informações contínuas, monitoramento e planejamento sistemático, formação de redes de contatos, independência e autoconfiança.

Ainda que a atitude empreendedora esteja presente desde os primórdios do ser humano, se faz cada vez mais necessária na Sociedade da Informação, tanto pela questão da competitividade e da inovação, quanto pela questão social e qualidade de vida. Diversos setores da economia tem despertado interesse pelo tema e começaram a adequar práticas empreendedoras para suas áreas, o que tem funcionado e agregado valor à sociedade. O conceito atual demonstra que é possível aplicar a inovação e o empreendedorismo em diversas áreas e atividades, contribuindo assim, para o crescimento e desenvolvimento do país.

Dessa forma, estão desenvolvendo-se diversos tipos de empreendedorismo, como fica claro a seguir:

a) empreendimentos empresariais: estão diretamente ligados a criação de empresas e geração de lucro ao empreendedor. Esse tipo de empreendimento gera empregos, movimenta a economia e agrega valor a sociedade. A inovação é muito importante no meio competitivo das empresas, garantindo muitas vezes sua permanência ou não no mercado. Os empreendimentos empresariais podem ser classificados em: empreendimentos comerciais, industriais e prestação de serviços (SALIM; SILVA, 2010);

b) empreendedorismo corporativo intraempreendedorismo: acontece quando a empresa já está bem estabelecida no mercado e precisa buscar na inovação de produtos, serviços, marketing, e etc., formas de continuar seu desenvolvimento. Nessa modalidade o capital intelectual dos funcionários é utilizado de modo colaborativo para definir a necessidade dos clientes, perceber os pontos fortes e fracos de cada setor e desenvolver propostas inovadoras que possam contribuir para a empresa a que faz parte. Segundo David (2004, p. 16) "o intraempreendedorismo representa uma enorme mudança de mentalidade dentro da empresa: a substituição do espírito conservador e burocrático por um espírito de empreendimento profissional e de realização pessoal";

c) empreendedorismo social: está muito atrelado a instituições do chamado terceiro setor, que são instituições sem fins lucrativos que tem sua atuação na área social. Conforme David (2004, p. 50) "o empreendedor social [é] 
visto como o responsável na busca de soluções para os mais variados problemas sociais, apresentando-se como um agente ativo e transformador dos valores da sociedade". Pode ser praticado por instituições privadas através da responsabilidade social, investindo em soluções de desenvolvimento sustentável e projetos culturais, visando melhorar a relação entre sociedade, empresa e meio ambiente;

d) empreendedorismo cultural: conforme Limeira (2008) são exemplos as ações realizadas em museus, teatros, orquestras, bibliotecas, entre outros centros culturais. Empreender na área cultural demanda os mesmos princípios dos demais empreendimentos e outros devem ser adequados a cada realidade, entretanto, o foco continua sendo a inovação agregando valor à sociedade.

Todos os tipos de empreendedorismo acima podem contribuir muito para o desenvolvimento de comunidades e cidadãos, tanto na parte da economia com na geração de inovações, empregos, prestação de serviços e progresso da nação, quanto na parte social, que visam atender as demandas sociais para a qualidade de vida, responsabilidade social, cultural e promoção da cidadania. Nesta pesquisa, o foco foi o empreendedorismo cultural que pode ser desenvolvido nas bibliotecas escolares por meio da inovação nas ações.

\section{Biblioteca escolar}

Segundo Araújo e Oliveira (2005) as bibliotecas existem há muito tempo na história da humanidade e ao longo dos séculos vivenciou mudanças significativas na sociedade e nos modos de encarar a informação.

A biblioteca escolar faz parte da organização escolar e deve existir de forma a contribuir com toda a comunidade envolvida. Segundo Durban Roca (2012, p. 10) "a biblioteca escolar deverá responder às atuais necessidades das escolas. Deverá ancorar-se no sistema educacional ao articular-se como recurso educativo facilitador que gera possibilidades reais de apoio ao trabalho docente [...]". Ou seja, a biblioteca escolar deve acompanhar todos os objetivos e necessidades da escola e participar ativamente no seu cotidiano precisam ser reconhecidas e efetivadas como um ambiente essencial ao processo de ensino-aprendizagem, influenciando positivamente no ensino básico, dessa forma, suas atividades devem estar intrínsecas ao global da escola e da comunidade, universalizando o conhecimento.

Dessa forma, deve ser um organismo vivo dentro da escola, um local recreativo, educativo e descontraído, ambiente de silêncio, estudo e também de conversas, histórias e debates. A biblioteca deve facilitar o desenvolvimento de conhecimentos de diversas áreas, atuar de forma 
colaborativa com professores auxiliando a formação da competência informacional de alunos e cidadãos.

A biblioteca escolar por ser muitas vezes o primeiro contato das crianças com o conhecimento deve, segundo Thiesen (2016, p. 17) "se constituir em lugar dinâmico e propositivo com atuação criativa e inovadora nas interfaces e mediações dentre as várias atividades educativas planejadas e desenvolvidas na/pela escola [...]" Na mesma linha de pensamento, Ledo e Ulbricht (2010) afirmam que um dos desafios da educação moderna é estimular a criatividade. A educação formal brasileira ainda tem como característica a repetição, reprodução e memorização de conhecimentos não contribuindo para o avanço da criatividade. Dessa forma, essas crianças e adolescentes posteriormente tornam-se adultos que simplesmente repetem o que aprendem, acreditando que não possui alternativa e poder para criar inovações.

Esse perfil de profissional e de cidadão não é o esperado pelo mercado de trabalho em plena Sociedade da Informação. A educação possui um papel primordial no progresso desse cidadão criativo e precisa mudar a forma de abordar seus conteúdos, de forma que o conhecimento seja compartilhado e construído em conjunto, não apenas repetido. A Sociedade da Informação necessita de cidadãos que sejam essencialmente criativos, empreendedores e independentes, por isso a educação pensada para atender as demandas da Sociedade da Informação deve possuir e desenvolver em seus educandos habilidades que promovam a criatividade, visando aprimorar os conhecimentos referentes ao pensamento empreendedor e o espírito inovador.

Para que a revolução da educação formal possa ocorrer é preciso haver também mudanças internas. A gestão dessas instituições precisa ser orientada ao empreendedorismo, só assim a escola poderá direcionar suas atividades e processos para a educação de jovens criativos, inovadores e empreendedores. A biblioteca escolar tem a possibilidade de abertura de novos caminhos e oportunidades por meio de atividades e serviços que podem ser oferecidos abarcando o objetivo desta pesquisa.

\section{Procedimentos metodológicos}

Esta pesquisa possui caráter exploratório e descritivo, com abordagem qualitativo-quantitativa com aplicação de questionário envolvendo coleta de dados com os bibliotecários e responsáveis por bibliotecas escolares públicas e privadas em Florianópolis.

Em relação aos meios é uma pesquisa bibliográfica que envolveu uma coleta de dados com a aplicação de um questionário que tratavam sobre: perfil dos respondentes; atividades desenvolvidas da biblioteca escolar; percepções sobre a inovação e produtos e/ou serviços inovadores existentes em seu ambiente de trabalho, estas questões visaram atender os objetivos da pesquisa. A técnica de análise de conteúdo foi usada para o tratamento dos dados qualitativos.

O universo desta pesquisa caracteriza-se como sendo as bibliotecas escolares registradas no site da Rede de Bibliotecas da Prefeitura do 
município de Florianópolis e as escolas privadas afiliadas ao Sindicato das Escolas Particulares de Santa Catarina (SINEPE/SC) em Florianópolis.

Foram localizadas 36 escolas públicas no site da prefeitura de Florianópolis. Entretanto, foi possível fazer contato com apenas 15 bibliotecários, destes, somente 13 responderam.

Em relação as escolas privadas foram localizadas no site do SINEPE 46 escolas. Foi feito contato telefônico com todas elas, entretanto foram eliminadas 18 do universo desta pesquisa, pois, encontravam-se fechadas ou tratavam-se de escolas de Ensino Superior, Ensino Infantil ou Ensino de Línguas, não caracterizando o foco do estudo. Deste total, 28 escolas tinham condições de participar da pesquisa, por isso foi enviado por email o questionário para os responsáveis pela biblioteca escolar e somente 14 responderam

Dessa forma, o universo constituinte desta pesquisa caracterizou-se por 27 respondentes oriundos das bibliotecas escolares públicas e privadas de Florianópolis.

\section{Apresentação e discussão dos resultados}

Esta seção está organizada conforme os objetivos específicos desta pesquisa que foram: a) Identificar práticas inovadoras em bibliotecas na literatura; b) Verificar ações inovadoras realizadas nas bibliotecas escolares públicas e privadas em Florianópolis; c) Descrever ações inovadoras que podem ser realizadas no âmbito das bibliotecas escolares. Dessa forma, os próximos tópicos seguem esta ordem.

\subsection{Prátivas inovadoras em bibliotecas}

Este tópico busca demonstrar alguns relatos de experiências ou pesquisas realizadas no âmbito das bibliotecas que trazem propostas inovadoras e/ou criativas para estes ambientes. Para isso, antes de realizar qualquer atividade na biblioteca o bibliotecário ou responsável deve prioritariamente conhecer o seu público. Elaborar pesquisas de satisfação, conhecer as necessidades e prioridades informacionais, esclarecer as dificuldades, e só então criar produtos ou serviços que contribuam para a plena satisfação do interagente. A parceria com professores e outros profissionais da escola é muito necessária para realizar um trabalho interdisciplinar que proporcione uma aprendizagem significativa e contextualizada.

A biblioteca escolar é um ambiente que deve proporcionar a criação, a criatividade, o trabalho cooperativo, a produção de conhecimento e cultura. É onde a criança deve aprender a gostar de ler e de aprender. Nesse contexto devem se inserir atividades que proporcionem 0 desenvolvimento dessas competências nos jovens. Para isso, as atividades precisam ser planejadas de forma que realmente desenvolvam habilidades e conhecimentos nas crianças nas diversas fases do aprendizado. Por isso, é tão importante a parceria com os professores, pois juntos, os 
profissionais podem pensar estratégias para desenvolver as habilidades cognitivas e criativas dos alunos.

Sendo assim, encontrou-se o relato de Pacheco (2006), que desenvolveu atividades de incentivo a leitura na Biblioteca Escolar Monteiro Lobato da Escola Desdobrada Retiro da Lagoa da Prefeitura Municipal de Florianópolis, com alunos de séries iniciais. Para a atividade relatada foi utilizado um retroprojetor como instrumento auxiliar da atividade de hora do conto.

O retroprojetor deixou de ser uma peça decorativa na biblioteca e passou a ser a peça fundamental para a narração de histórias, chamando a atenção da criançada a cada transparência projetada, pois facilitava a observação das ilustrações por todos de uma só vez. Assim, iam comentando e se deliciando com as imagens. A cada momento ouvia-se um "olha que legal!"; deste modo descobriu-se uma nova forma de despertar o interesse pelo mundo encantado da leitura (PACHECO, 2006, p. 345).

Além disso, posterior as contações de histórias, as crianças realizavam atividades de fixação: produção de textos, pesquisas, desenhos, entre outras (PACHECO, 2006). Dessa forma, é possível trabalhar o imaginário durante a hora do conto e já as atividades despertam a criatividade e exercitam a sociabilidade trabalhando em equipe, além de essas atividades descontraídas auxiliarem posteriores trabalhos onde as crianças deveram produzir textos, pesquisar e desenvolver o senso crítico.

Outra experiência foi relatada por Burin e Lima (2013), realizada na Biblioteca do Instituto Federal de Santa Catarina - Campus Lages, onde foi instituído o projeto "Arte e Cultura na Biblioteca". Segundo os autores as atividades tiveram objetivo de proporcionar a comunidade geral da região atividades que pudessem gerar aperfeiçoamento e transformação social. Para realizá-las a equipe buscou parcerias e realizaram exposições, palestras, cinema e oficinas. Teve copa de xadrez, exposição sobre folclore, exposições itinerantes, revolução farroupilha, oficina literária, exposição arte de brincar, entre outras que mostra o estabelecimento de parcerias com outras instituições e a valorização da cultura serrana como foco de determinadas atividades.

As atividades são todas descritas no artigo, ficando claro Conforme Burin e Lima (2013), para a Copa de Xadrez estabeleceu-se parceria com a Federação Catarinense de Xadrez e houve participação de enxadristas da região serrana e de outros municípios; as exposições itinerantes foram de obras de artistas catarinenses e ocorreram em parceria com o SESC; na exposição sobre folclore, homenageou-se uma lenda lageana da serpente do tanque, a serpente foi montada na biblioteca e em seu interior expostas esculturas, contação de lendas, feitas em parceria com grupo da terceira idade do Bairro São Francisco e exibição do documentário "A lenda da serpente do tanque"; já exposição da Revolução Farroupilha, buscou gerar debates com o intuito de despertar o senso crítico, além disso, ocorreram contação de casos da revolução, música 
típica da Região, lançamento de livro e exposição de objetos da história da Revolução Farroupilha; a oficina literária contou com decoração de Haloween, os participantes precisavam vir fantasiados para apresentar a história de um livro, o objetivo da oficina foi debater sobre livros com temas de fantasia e desenvolver técnica de redação em grupo.

Outra iniciativa encontrada na literatura foi publicada por Ferreira e Santana (2013), realizada na Biblioteca do Centro de Educação Básica, em Feira de Santana (BA). As atividades desenvolvidas foram: o projeto Cuida de Mim, onde crianças das séries iniciais ficam responsáveis por um animalzinho de brinquedo, durante uma semana. O animal acompanha uma carta explicativa endereçada aos pais, sobre a atividade e um caderno, no qual a criança precisa contar sua experiência com o brinquedo. No fim do ano é lançado um livro contendo as produções. Esta atividade possui objetivo de incentivar a escrita de maneira lúdica e divertida. Outro projeto é o Passaporte Biblioteca, que busca incentivar o hábito de ler. Os livros retirados para empréstimo domiciliar são registrados no Passaporte Biblioteca com um carimbo e o visto do funcionário da biblioteca, quando o aluno completa seu passaporte recebe um brinde que também tem ligação com a leitura ou escrita; na biblioteca também é realizada exibição de filmes que abordem temas para reflexão; o projeto de contação de histórias intitula-se conhecendo novos mundos com a leitura, além da contação também são feitas rodas de leitura e discussão de reflexões sobre temas abordados nos livros, visando a formação crítica dos alunos.

As práticas relatadas acima pretendem principalmente incentivar a leitura e a escrita no cotidiano dos alunos, de modo a tornarem-se hábitos. Entretanto, para que as escolas consigam instigar os alunos nessas práticas é preciso criatividade nas abordagens, pois quando a leitura é instituída como obrigação muitas vezes acaba gerando distanciamento e repúdio.

A experiência divulgada por Garcez (2006) ocorreu na biblioteca Cláudio Luciano Fernandes do Colégio Policial Militar Feliciano Nunes Pires em Florianópolis, Santa Catarina. O projeto foi intitulado: Orientação à pesquisa escolar aos alunos de $5^{a}$ série do Ensino Fundamental e surgiu da visível necessidade dos alunos em pesquisar para desenvolver trabalhos escolares, já que a prática do copiar e colar é muito comum nas escolas, devido à falta de instrução a pesquisa.

O projeto buscou capacitar para pesquisa escolar; esclarecer sobre fontes de informação; apresentar as etapas de um trabalho; informar sobre direito autoral; citação e referência bibliográfica. Ainda conforme a autora, os conteúdos foram ministrados em sala de aula e posteriormente foram realizadas atividades e exercícios na biblioteca. Como resultado os alunos deveriam utilizar-se do que foi aprendido, seguindo a estrutura e a padronização de um trabalho de pesquisa.

Este relato diferencia-se dos demais, por tratar mais especificamente da importância de cultivar bons hábitos de pesquisa desde cedo nos jovens, informando-os sobre fontes confiáveis, sobre questões de plágio e, além disso, desenvolver métodos que os façam ler, 
pensar para posteriormente escrever, reforçando a criticidade e minimizando os hábitos de cópias.

Ressalta-se que para a efetividade e continuidade de projetos deste aspecto é de extrema importância o trabalho em colaboração com os professores, tanto para auxiliar durante a realização das oficinas, quanto para perpetuar estas práticas nos futuros trabalhos escolares.

\subsection{Atividades desenvolvidas nas unidades de informação}

Ao aplicar o questionário nas escolas públicas e privadas escolares de Florianópolis foi possível identificar as atividades mais realizadas no cotidiano das bibliotecas escolares pesquisadas. Esta questão permitiu aos respondentes que assinalassem mais de uma afirmativa. Havia várias opções relacionadas ao planejamento de atividades e eventos, participação em reuniões pedagógicas, ações com a comunidade, etc. Porém, as opções mais assinadas foram: Organização do acervo (100\%), Recepção e atendimento (96\%), Incentivo à leitura e formação de leitores $(93 \%)$, catalogação, classificação e indexação $(85 \%)$, serviço de referência e pesquisa (78\%), ações culturais (74\%).

É possível perceber que as atividades mais realizadas ainda estão ligadas ao paradigma do acervo. O acervo é parte constituinte do todo de uma biblioteca, entretanto, não ser este apenas o seu cerne. As bibliotecas existem para as pessoas, e seus serviços devem ser oferecidos visando auxiliá-las de alguma forma.

É possível visualizar que o tratamento do acervo faz parte das dimensões inerentes à biblioteca escolar, entretanto, os serviços devem ser diversificados visando contemplar todas as dimensões recreativas, sociais, informativas, pedagógicas para tornar a biblioteca realmente integrante no processo de ensino-aprendizagem. Segundo Gonçalves e Silva (2009, p. 422):

O problema é que a maioria dos profissionais está mais voltada para as tarefas estritamente técnicas, como, por exemplo, o tratamento técnico, a normalização, e outros, e não desprende o tempo necessário para incentivar o uso da criatividade. Há várias outras barreiras que inibem o pensamento criativo nas bibliotecas como a falta de motivação, desconfiança, medo de errar, medo da crítica, e, principalmente, o comodismo.

Este cenário é muito comum tanto em bibliotecas, quanto em outros setores, pois muitas vezes os profissionais acomodam-se com seu trabalho e não percebem maneiras de inová-lo ou melhorá-lo. Este fato somado a uma cultura organizacional hierárquica e burocrática gera em muitos casos indisposição a mudança e acomodação.

Para evitar que isso aconteça existe uma grande influência do comportamento e perfil do bibliotecário ou responsável pela biblioteca escolar. Este profissional precisa ter claro os objetivos e dimensões da biblioteca escolar e dedicar-se para alcança-las, buscando estratégias que 
burlem o comodismo e façam a biblioteca escolar acontecer efetivamente como espaço para aprendizagem, construção de conhecimento e acesso à cultura.

\subsection{Atividades periódicas na biblioteca escolar}

Com a aplicação do questionário também foi possível mapear a existência de projetos ou disciplinas que utilizam de forma periódica o espaço e/ou os serviços da biblioteca escolar, ou seja, entender se os alunos são levados periodicamente ao espaço sobre mediação para desenvolverem atividades diferenciadas e principalmente conhecer quais são essas atividades, desse modo, verificar a presença de iniciativas criativas e inovadoras que objetivem a promoção da leitura e da aprendizagem.

Sendo assim, nesta questão a maioria dos respondentes (74\%) afirma que existem atividades ou disciplinas que se utilizam do espaço da biblioteca escolar com periodicidade conforme quadro a seguir:

Quadro 1 - Descrição das atividades

\begin{tabular}{l|l}
\hline \multicolumn{1}{c|}{ Tipo de atividades } & \multicolumn{1}{c}{ Conteúdos } \\
\hline \hline $\begin{array}{l}\text { Aulas ministradas na } \\
\text { biblioteca }\end{array}$ & $\begin{array}{l}\text { Professores levam seus alunos para realizarem na biblioteca atividades como: Incentivo à leitura; } \\
\text { Retirada de livros; Leitura local; Dar aula }\end{array}$ \\
\hline Produção de textos & O espaço da biblioteca é utilizado para atividades como: Produção de redações; Fichas de leitura \\
\hline Hora do conto & $\begin{array}{l}\text { Esta atividade é principalmente realizada com turmas de Educação Infantil e Fundamental I. } \\
\text { Realizadas por professoras, bibliotecárias, contadoras de histórias convidadas ou pelos próprios } \\
\text { alunos }\end{array}$ \\
\hline Orientação à pesquisa & $\begin{array}{l}\text { Atividades de incentivo a pesquisa: Orientação sobre utilização da biblioteca; Visita guiada; } \\
\text { Leitura de jornais, revistas e periódicos; Projetos de pesquisa: definição do tema, objetivos, } \\
\text { pesquisa bibliográfica, etc. }\end{array}$ \\
\hline Projetos culturais & Sarais literários; Café literário, Exposições, Sessão de cinema; Momento Musical \\
\hline Diferenciadas & $\begin{array}{l}\text { Propaganda literária: alunos do Fund. I preparam a propaganda de um livro; Clube do livro; } \\
\text { Conversa com autores convidados; Projetos de artes }\end{array}$ \\
\hline
\end{tabular}

Fonte: Dados da pesquisa (2016).

É possível perceber que as respostas foram bem variadas e ressaltase que algumas escolas desenvolvem mais de uma dessas atividades com diferentes turmas e séries ao longo do ano, além de participarem na promoção de eventos escolares.

Este quadro foi elaborado por similaridade das respostas, agrupando atividades comuns entre as bibliotecas, entretanto, é importante salientar que nem todas as bibliotecas escolares desenvolvem todas estas atividades, porém optou-se por este tipo de apresentação para melhor visualizar o panorama geral do que os profissionais do município de Florianópolis têm desenvolvido. 
Conforme 0 quadro percebe-se que existem atividades que permeiam diversos contextos como: incentivo à leitura; competência informacional; acesso à cultura e interação com a comunidade. Dessa forma, é possível inferir que existe a possibilidade dos profissionais destes ambientes proporcionarem a seus interagentes todas as dimensões da biblioteca escolar formando assim, cidadãos criativos, críticos e empreendedores.

Pode-se considerar que determinadas atividades realizadas periodicamente pelos respondentes mantém a biblioteca escolar bem entrosada nas diversas atividades do cotidiano escolar, demonstrando preocupação em contribuir com a formação dos alunos.

\subsection{Percepções sobre a inovação}

Foi questionada as percepções dos respondentes em relação às inovações quais os maiores obstáculos para inovar e como buscam informações em relação às práticas. A grande maioria (48\%) afirma que "Às vezes" a instituição em que atuam se mostra inovadora. Quanto ao fato de investirem em capacitação profissional também foi identificado pela maioria que "Às vezes" isso acontece (33\%). Sobre a possibilidade de atuar de com autonomia na realização de suas atividades, a maioria afirma que frequentemente $(48 \%)$ ou sempre $(41 \%)$ isto ocorre.

Esses resultados demonstram aspectos significativos para proporcionar um ambiente inovador. Um ambiente que valoriza e dá autonomia ao funcionário pode contribuir para deixá-lo a vontade para pensar sobre como a instituição está no momento, e como pode melhorar. Quando isto torna-se uma cultura na organização, esta proporciona que todos os seus funcionários pensem, planejem, colaborem e efetivem melhoras em seu ambiente de trabalho gerando valor e inovações.

Para que os profissionais possam transformar essa realidade e modificar o pensamento dos gestores em relação a mudança é necessário adotar estratégias de atuação de demonstrem a importância de seu trabalho. Além disso, os profissionais não devem acomodar-se a um ambiente estável, ele deve buscar atualizar-se, trazer ideias novas e experimentá-las, buscar parcerias que o apoiem e registrar os resultados das atividades que realiza visando demonstrar a importância da sua atuação.

Outra questão referia-se a percepção dos respondentes em relação a sua própria atuação. Dessa forma, sobre acreditarem ser possível inovar em suas práticas as respostas foram otimistas e $56 \%$ afirma que sempre é possível inovar nas atividades que realizam.

$\mathrm{Na}$ questão seguinte, sobre os profissionais realmente buscarem inovar em suas práticas, foi possível verificar uma maior dispersão entre as respostas, sendo que a maioria afirma que frequentemente $(33 \%)$ ou às vezes $(30 \%)$ realizam atividades inovadoras. Ainda assim, nenhum deles declarou que não realiza nenhuma atividade inovadora nunca, isto pode demonstrar que apesar das dificuldades cotidianas, todos os respondentes procuram contribuir com ações na biblioteca escolar. 
Entretanto pode-se perceber que apesar de acreditarem na possibilidade de inovar, de possuírem certa autonomia, aparentemente estes profissionais ficam presos aos impedimentos. Os profissionais devem buscar oportunidades porque é por meio da atitude que as mudanças podem vir a acontecer.

Os profissionais podem inovar de diversas formas, não necessariamente fazendo algo extremamente radical, mas se espelhando em atividades de outros profissionais ou bibliotecas que possam agregar valor também no seu contexto. Como exposto anteriormente, a inovação e a criatividade são acontecimentos atitudinais do profissional que precisa engajar-se e fazer acontecer, dar visibilidade ao seu trabalho, não acomodando-se nas rotinas.

A questão seguinte procurou identificar quais são os maiores obstáculos, na percepção dos respondentes, para que possam efetivamente realizar práticas inovadoras. Constatou-se que os recursos financeiros $(83 \%)$, desinteresse e resistência as mudanças $(33 \%)$, ausência de planejamento institucional (30\%) e cultura organizacional (25\%) foram apontadas como as principais dificuldades que impedem a maior efetivação de práticas inovadoras nas bibliotecas escolares pesquisadas.

A falta de recurso financeiro não deve ser usada como argumento para não inovar, visto que os profissionais devem buscar parcerias com outras instituições, com a comunidade, com os pais e demais profissionais para desenvolver ações nas bibliotecas escolares como apresentado no relato de Burin e Lima (2013). Além disso, existem diferentes formas de captar recursos para obter auxílio financeiro com empresas privadas e agências de fomento.

Em relação à percepção dos respondentes sobre as vantagens de inovar, pode-se perceber que a grande maioria dos respondentes acredita que entre as maiores vantagens de inovar no seu ambiente de trabalho estão: atender melhor as necessidades dos usuários (78\%); melhorar o ambiente de trabalho (59\%) e o interagente sentir-se parte da biblioteca (55\%). Nota-se também que nenhum deles desconsidera que a inovação não seja uma vantagem.

\subsection{Produtos e/ou serviços inovadores}

Neste tópico procurou-se identificar no discurso e na percepção dos respondentes quais eram os produtos ou serviços mais inovadores, criativos ou diferenciados que são oferecidos em seus respectivos ambientes de trabalho.

Quadro 2 - Produtos e/ou serviços inovadores

\begin{tabular}{l|l}
\hline \multirow{4}{*}{ Mais se destacaram } & $\begin{array}{l}\text { R19: "A contadora de história sempre elabora atividades na contação..as vezes com vista a percepção } \\
\text { da criança..como o conto sobre a deficiência visual..onde foi mostrado livros em braile e foi utilizado } \\
\text { uma caixa para a criança identificar objetos pelo tato. São ações inovadoras q abrangem o } \\
\text { conhecimento infantil". }\end{array}$ \\
\cline { 2 - 2 } & $\begin{array}{l}\text { R23: "Projeto Momento Musical - Banda Biblio [...]. Visa proporcionar momentos de apreciação e } \\
\text { aprendizagem, onde os alunos interagem de forma descontraída e lúdica através da literatura e da } \\
\text { música [...]". }\end{array}$ \\
\hline
\end{tabular}




\begin{tabular}{c|l}
\hline \multirow{4}{*}{ Menos se destacaram } & $\begin{array}{l}\text { R26: "Procurei criar na biblioteca o maker space. Onde faço exposição. Jogos e até oficinas. E um } \\
\text { espaço do saber e do saber fazer". }\end{array}$ \\
\hline & R2: "Computadores". \\
\cline { 2 - 2 } & R3: "Acesso às informações". \\
\cline { 2 - 2 } & R13: "Atualmente os E-books". \\
\cline { 2 - 2 } & R17: "Disposição de empréstimos do acervo". \\
\cline { 2 - 3 } & $\begin{array}{l}\text { R24: "Qualquer projeto /atividade que não está relacionada diretamnete com as atividades diárias da } \\
\text { biblioteca como empréstimo, auxilio á pesquisa... na atual circunstancia, já considero inovador". }\end{array}$ \\
\hline & Fonte: Dados da pesquisa (2016).
\end{tabular}

Segundo o quadro, as respostas que mais se destacaram trazem em seu conceito atividades que diferiram-se significativamente das demais, não sendo consideradas comuns. É possível perceber, que estes profissionais detalharam melhor as atividades deixando claro por que as consideravam inovadoras. Além disso, nota-se que possuem relação com a experiência do interagente dentro do ambiente da biblioteca escolar, indo além do mero acesso a documentos e produção de trabalhos escolares.

Estas atividades de destaque promovem a cultura e a aprendizagem, além de possibilitar o desenvolvimento de habilidades artísticas que geralmente não são comtempladas no currículo. Pode-se inferir que existe a preocupação com que os alunos participem ativamente das ações realizadas não sendo apenas espectadores. Em contrapartida, as demais respostas foram enquadradas como menos inovadoras, pois apresentam produtos e serviços que por si só não configuram este aspecto e, além disso, o discurso dos próprios profissionais apresenta-se desmotivado.

\subsection{Propostas de ações inovadoras}

A partir do levantamento bibliográfico e da coleta de dados nas bibliotecas escolares públicas e privadas é possível apresentar ideias e/ou propostas que possam ser implementadas ou adequadas em seus contextos com objetivo de dinamizar as inovações nestas bibliotecas5, de modo a aproximar toda comunidade escolar da biblioteca, possibilitando que a mesma cumpra seu papel social.

As escolas são ambientes de aprendizagem, de pesquisa, de formação, sendo assim, deveriam desenvolver com maior apreço a pesquisa escolar, ou seja, cultivar desde cedo nas crianças e jovens bons hábitos de pesquisa, minimizando práticas tão comuns quanto o "copia e cola" e a "decoreba", que geram o posterior esquecimento. Os estudantes devem aprender a pesquisar, a desenvolver o pensamento crítico, de modo a assimilar os conhecimentos, não apenas para serem aprovados.

Dessa forma, caracteriza-se competência informacional segundo Campello (2006) como, o desenvolvimento de habilidades necessárias à sociedade contemporânea visando promover a recuperação de fontes confiáveis diante da abundância de informação e o uso crítico das mesmas pelos indivíduos.

É de extrema importância que os futuros cidadãos do século XXI saibam utilizar a informação, visto que, cresce cada vez mais as formas 
de se comunicar e trocar experiências, é necessário que as crianças desenvolvam estas habilidades não apenas para pesquisas escolares, mas para a vida, lançando um olhar crítico sobre toda a informação que chega, reconhecendo fontes confiáveis e formando seu próprio pensamento.

Deste modo, a competência em informação é um movimento que reconhece o papel da biblioteca no desenvolvimento destas habilidades, entretanto, são necessárias ações para efetivar a assimilação destes conhecimentos por parte dos alunos.

Uma ótima oportunidade para empreender e experimentar, que pode contribuir para desenvolver a aprendizagem por meio da recreação é criar espaços de makerspace. Os makerspace, segundo Portal... (2015) são espaços de criação, ou seja, é possível elaborar oficinas que promovam a recreação auxiliando o desenvolvimento de conhecimentos. No Brasil, o termo pode ser traduzido como ambiente de aprendizagem ou laboratório.

Ao contrário do que o conceito possa sugerir, estes espaços não devem ter equipamentos caros e sofisticados, dos quais algumas bibliotecas em seus contextos atuais não possuem condições de arcar. Podem ser construídos de forma colaborativa, com itens simples que possuam o objetivo de estimular a criatividade e aprender fazendo e se divertindo dentro das bibliotecas.

Este espaço deve ofertar atividades diferenciadas com cunho criativo que abordem temas de utilidade aos estudantes: acessibilidade, desenvolvimento sustentável, engenharia, artes, serigrafia, entre diversas outras possibilidades.

É necessário que a biblioteca inove de modo a acompanhar as mudanças da sociedade, contribuindo para a evolução da aprendizagem que já não deve ser estática e sim dinâmica. Os espaços maker auxiliam na interação entre as pessoas e os objetos oferecendo a oportunidade de criar conhecimento de forma colaborativa.

A inserção de jogos de vídeo game em bibliotecas também pode ser estratégia para atrair interagentes e promover a inovação em bibliotecas escolares. O fato de haver recreação explícita na biblioteca atrai as pessoas para utilização de seus espaços para lazer, com esta aproximação é mais fácil que as pessoas conheçam os serviços oferecidos e desenvolvam hábito de frequenta estes ambientes.

Os videogames são fonte de entretenimento e comunicação, como vantagens pode-se destacar segundo Vieira, Passos e Rockiki (2009): estimulo a imaginação; superação de obstáculos; experiência na tomada de decisão, entre outras.

Dessa forma, estes instrumentos devem ser pensados como objetos que podem ser auxiliares do ensino aprendizagem, assim como os filmes, a música e a internet e devem fazer parte das coleções das bibliotecas para promover uma inovação na aprendizagem e ensino de diferentes formas.

Visto que, um dos principais impedimentos apontados para a inovação nas bibliotecas é a falta de recursos, principalmente financeiros, 
este tópico pretende contribuir com maneiras de captar recursos externos para investir em atividades nestes ambientes.

As principais fontes de financiamento segundo Goldschmidt e Calfat (2014, p. 60), são: "indivíduos (pessoas físicas); empresas; fundações (internacionais e nacionais); instituições religiosas; Governo e projetos de geração de renda", além da Lei Rouanet. Todas essas fontes possuem perfis diferenciados, com isso, a instituição deve redigir um projeto que esclareça suas necessidades aos possíveis doadores e, além disso, deve viabilizar qual o investidor mais adequado ao seu tipo de necessidade.

Outra possibilidade além da captação de recursos financeiros é estabelecer parcerias com outras instituições de diversos setores para obtenção de mobiliário, equipamentos, materiais, ente outros. Para isso é necessário estabelecer redes de contatos e esclarecer os benefícios mútuos entre os envolvidos.

Entretanto, para que haja viabilidade de qualquer captação de recursos, os profissionais precisam realizar pesquisas que os auxiliem a montar projetos para as atividades, fazer orçamentos e encontrar possíveis investidores. As possibilidades existem, os recursos existem, cabe ao profissional pró-atividade para capta-los dentro e fora de suas instituições.

\section{Considerações finais}

O presente estudo foi elaborado visando analisar as práticas inovadoras nas bibliotecas escolares públicas e privadas em Florianópolis. Além disso, pretendeu identificar práticas inovadoras em bibliotecas na literatura visando demonstrar como é possível inovar nas práticas cotidianas das bibliotecas escolares por meio dos relatos de experiência; verificar ações inovadoras realizadas nas bibliotecas escolares públicas e privadas em Florianópolis.

Para isto aplicou-se questionário com estes profissionais e, a partir do mesmo, analisaram-se as respostas obtendo-se assim, um panorama geral das atividades que vem sendo desenvolvidas no município e, por fim, elencaram-se ações inovadoras que podem ser realizadas no âmbito das bibliotecas escolares desejando ampliar a visão dos profissionais em relação ao processo de ensino aprendizagem e como o mesmo pode ser abordado de maneira lúdica, induzindo a produção de novos conhecimentos contribuindo assim, para a formação cidadã. Sendo assim, compreende-se que todos os objetivos propostos por esta pesquisa foram atingidos.

Conclui-se sobre os resultados obtidos da pesquisa aplicada, que as práticas inovadoras nas bibliotecas escolares em Florianópolis ainda caminham timidamente em meio a obstáculos cotidianos enfrentados pelos profissionais. No entanto, foi possível perceber em algumas respostas o interesse dos mesmos em contribuir cada vez mais com o ambiente escolar, portanto, acredita-se que com inspiração e motivação existem condições suficientes para transformar essa realidade. 
Ressalta-se que é compreensível que as tarefas cotidianas e técnicas dificultam a dedicação mais efetiva a outras atividades extras, ainda assim, acredita-se que um profissional engajado que acredita no potencial de seu trabalho possa contribuir ainda mais com a educação e a formação dos cidadãos.

Com isso, o diferencial desta pesquisa foi mapear e apresentar ações inovadoras que acontecem e que podem acontecer nas bibliotecas escolares, na esperança de servir como incentivo aos profissionais visando que busquem transformar a realidade das bibliotecas, das escolas, da educação e por fim, dos indivíduos. Espera-se que esta pesquisa seja utilizada pelos profissionais do dia a dia, na expectativa de incentivá-los de alguma forma a ir além e acreditar que suas práticas possam efetivamente mudar a comunidade.

\section{Referências}

ARAÚJO, E. A.; OLIVEIRA, M, de. A produção de conhecimentos e a origem das bibliotecas. In: OLIVEIRA, M. (Coord.) et al. Ciência da informação e biblioteconomia: novos conteúdos e espaços de atuação. Belo Horizonte: Editora UFMG, 2005. p. 24-36.

BASTOS, M. F.; RIBEIRO, R. F. Educação e empreendedorismo social: um encontro que (trans)forma cidadãos. Rev. Diálogo Educ., Curitiba, v. 11, n. 33, p. 573-594, maio/ago. 2011.

BURIN, C. K.; LIMA, M. M. de. Arte e cultura na Biblioteca do Instituto Federal de Santa Catarina (IFSC), Câmpus Lages: uma experiência. In: CONGRESSO BRASILEIRO DE BIBLIOTECONOMIA, DOCUMENTAÇÃO E CIÊNCIA DA INFORMAÇÃO, 25., 2013, Florianópolis. Anais... Florianópolis: FEBAB, 2013. p. 37-47.

CAMPELLO, B. A escolarização da competência informacional. Revista Brasileira de Biblioteconomia e Documentação, São Paulo, v. 2, n. 2, p. 63-77, dez. 2006.

DAVID, D. E. H. Intraempreendedorismo social: perspectivas para o desenvolvimento social das organizações. 2004. 204f. Tese (Doutorado em Engenharia da Produção) - Programa de pós-graduação em Engenharia de Produção, Universidade Federal de Santa Catarina, Florianópolis, 2004.

DOLABELA, F. Pedagogia empreendedora. São Paulo: Cultura, 2003.

DURBAN ROCA, G. Biblioteca escolar hoje: recurso estratégico para a escola. Porto Alegre: Penso, 2012.

FERREIRA, M. do C. S. B.; SANTANA, I. C. N. Biblioteca escolar: estratégias para torná-la mais atraente. In: CONGRESSO BRASILEIRO DE BIBLIOTECONOMIA, DOCUMENTAÇÃO E CIÊNCIA DA INFORMAÇÃO, 25., 2013, Florianópolis. Anais... Florianópolis: FEBAB, 2013. p. 6- 10. 
GARCEZ, E. F. Orientação à pesquisa escolar aos alunos de $5^{a}$ série de escola pública estadual: relato de experiência. Revista $A C B$, Florianópolis, v. 11, n. 1, p. 205-220, jan./jun. 2006.

GOLDSHMIDT, A.; CALFAT, S. Manual de captação de recursos. São Paulo: Apoena Sustentável, 2014.

GONÇALVES, P. de C.; SILVA, N. P. A criatividade nas unidades de informação. Revista $A C B$, Florianópolis, v. 14, n. 2, p. 407-428, jul./dez., 2009.

LEDO, R. Z.; ULBRICHT, V. R. O uso de hipervídeo como estímulo à criatividade no processo de aprendizagem. In: ULBRICHT, V. R.; VANZIN, T.; ZANDOMENEGHI, A. L. A. de O. Criatividade \& conhecimento. Florianópolis: Pandion, 2010. p. 123-136.

LIMEIRA, T. M. V. Empreendedor cultural: perfil e formação profissional. In: ENCONTRO DE ESTUDOS MULTIDISCIPLINARES EM CULTURA, 4., 2008, Salvador. Anais... Salvador, 2008.

MARIANO, S. R. H.; MAYER, V. F. Empreendedorismo: fundamentos e técnicas para criatividade. Rio de Janeiro: LTC, 2011.

ORGANIZAÇÃO PARA COOPERAÇÃO ECONÔMICA E DESENVOLVIMENTO DEPARTAMENTO ESTATÍSTICO DA COMUNIDADE EUROPÉIA (OECD). Manual de Oslo: diretrizes para a coleta e interpretação de dados sobre inovação. 3. ed. Brasília: FINEP, 2006.

PACHECO, R. Alternativas de incentivo à leitura: relato de experiência. Revista $A C B$, Florianópolis, v. 11, n. 2, p. 345-352, ago./dez. 2006.

PORTAL do bibliotecário. Bibliotecas como 'makerspaces'. 2015. Disponível em: <http://portaldobibliotecario.com/2015/07/20/bibliotecas-comomakerspaces/>. Acesso em: 12 nov. 2016.

SALIM, C. S.; SILVA, N. C. Introdução ao empreendedorismo: construindo uma atitude empreendedora. Rio de Janeiro: Elsevier, 2010.

SOUZA, V. A. B. de; LAPOLLI, É. M. O perfil criativo e o perfil empreendedor. In: ULBRICHT, V. R.; VANZIN, T.; ZANDOMENEGHI, A. L. A. de O. Criatividade \& conhecimento. Florianópolis: Pandion, 2010. p. 211-227.

THIESEN, J. da S. Prefácio. In: BLATMANN, U.; VIANNA, W. B. (Org.). Inovação em escolas com bibliotecas. Florianópolis: Dois por quatro, 2016.

THOMPSON, C. Grande ideia! São Paulo: Saraiva, 1993.

VIEIRA, R. Q.; PASSOS, J. dos R.; ROCKIKI, C. C. Videogames em biblioteca: discussões em jogo. In: SEMINÁRIO EM CIÊNNCIA DA INFORMAÇÃO, 3., 2009, Londrina. Anais... Londrina: Universidade Estadual de Londrina, 2009. p. 11. 